\title{
Estrogenic Joint Effect of BPA and DES on MCF-7 Cells
}

\author{
Hongping $\mathrm{Pu}^{1, \mathrm{a}}$, Xiaodong $\mathrm{Ma}^{1, \mathrm{~b}}$, Zhixiang $\mathrm{Xu}$, Jun Liu, Huang Bin, Dong Ren, \\ Huan He, Xuejun Pan*, 1, c
}

${ }^{1}$ Faculty of Environmental Science and Engineering, Kunming University of Science and Technology, Kunming 650500, Yunnan, China.

a1851788050@qq.com, b524839140@qq.com, cxjpan@kmust.edu.cn

Keywords: BPA; DES; estrogenic effect; joint effect; breast cancer cells

\begin{abstract}
Nowadays environmental health problems caused by Endocrine disrupting chemicals (EDCs) really attracted much concern. Bisphenol A (BPA) and diethylstilbestrol (DES), synthetic estrogens that have similar structure, were proved to be related to various type of cancers, including breast cancer. In this paper, cell viability assay was used as evaluation basis to examine the estrogenic effect and joint effect of BPA, DES and 17 $\beta$-estradiol (E2). The result showed that the proliferation of MCF-7 cells was promoted by environmental relevant doses of BPA and DES. And the more intense effect would be realized when combining BPA with DES. In addition, BPA or DES could strengthen the estrogenic effect of E2. However, for ternary mixture of E2, BPA and DES, all the experimental groups performed an antagonism.
\end{abstract}

\section{Introduction}

Endocrine disrupting chemicals (EDCs), a new type of pollutant, are exogenous agents that can interfere with the synthesis, secretion, transport, action, or elimination of natural hormones, which sustain development, reproduction, and behavior ${ }^{[1]}$. A great number of studies indicated that chronic or acute exposure to EDCs results in harmful health effects including birth defects, diabetes, cancers, reproductive problems, early puberty, and obesity ${ }^{[2]}$.

As a kind of EDCs, Bisphenol A (BPA) is one of the highest production-volume chemicals ${ }^{[3]}$, which ubiquitously present in the environment and resistant to degradation. Being widely used to manufacture polycarbonate plastics including food and beverage containers ${ }^{[4]}$, BPA can be detected not only in the environment (air, oil, water etc.), but also in human tissues such as urine, blood, fetal tissues, and amniotic fluid ${ }^{[5]}$. For instance, American scholars detected forty water samples over the United States with a BPA detection rate of $40 \%$, and the highest concentration reached $12 \mu \mathrm{g} / \mathrm{L}^{[6]}$. Otherwise, Ye et al. measured the urinary concentrations of BPA in 616 archived samples collected from convenience samplings of U.S. adults in 2000 to 2014, with the detection rate between 74\%-99\% and the concentration between $0.36-2.07 \mu \mathrm{g} / \mathrm{L}^{[7]}$. Therefore, it is no doubt that the exposure of BPA is universal and inevitable. In addition, a large of researches revealed that BPA influences multiple endocrine-related pathways and then causes various diseases such as obesity, sexual behavior, thyroid function, cancer, and neurological effects ${ }^{[8]}$.<smiles>CC/C(=C(/CC)c1ccc(O)cc1)c1ccc(O)cc1</smiles>

BPA

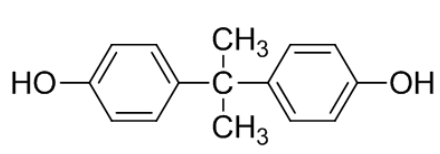

DES

Fig. 1. The chemical structure of BPA and DES.

Another interesting compound is diethylstilbestrol (DES), whose structure is very similar to BPA (shown in Fig. 1). In 1940s to 1970s, DES was produced as a medicine to prevent miscarriage and other complications of pregnancy. However, it turned out to be wrong, because a report discovered that some adolescent daughters of women who had taken DES while pregnant got reproductive tract 
cancer $^{[9]}$. After that, researches related to estrogenic effects and carcinogenicity of DES were developed.

For breast tissue, DES was proved to be associated with increased breast cancer risks in both daughters and their mothers ${ }^{[10]}$. But most of studies were focus on the prenatal expo-sure of animal model, discussing the estrogenic effect on offspring. Due to the similar structure to DES, BPA was proved to be associated with breast cancer in many articles. In most cases, high doses (micromolar range) BPA was used frequently. While studies of cellular effects on mammary cells exposed in low, environmental relevant doses of BPA are needed. On the other hand, the different estrogenic effects of these two structural similar EDCs were rarely reported. And then, the mixture effect of BPA and DES is almost unknown. Therefore, in this paper, we examined the diverse effects of BPA and DES exposure on breast cancer cell. In addition, the mixture effect of BPA and DES as well as the joint effect of BPA, DES and E2 were explored.

\section{Materials and Methods}

Chemicals. BPA, DES and dimethyl sulfoxide (DMSO) were purchased from Sigma Chemical Co. (St. Louis, MO, USA). BPA and DES was dissolved in DMSO to prepare a $10 \mathrm{mM}$ stock solution, and stored at $-20^{\circ} \mathrm{C}$. And then, diluted the stock solution with RPMI 1640 culture medium (Gibco BRL) without phenol red to the desired concentration we needed.

Cell Culture. The ER positive MCF-7 breast cancer cells which was obtained from Kunming Institute of Zoology, Chinese Academy of Sciences (Kunming, China) and maintained in RPMI 1640 culture medium (Gibco BRL) supplemented with heat-inactivated endotoxin-free $10 \%$ fetal bovine serum, $100 \mu \mathrm{g} / \mathrm{ml}$ streptomycin and $100 \mathrm{units} / \mathrm{ml}$ penicillin at $37{ }^{\circ} \mathrm{C}$ containing $95 \%$ air and $5 \% \mathrm{CO}_{2}$ atmosphere.

Cell Viability Assay ${ }^{[11]}$. Cells were seeded into each well of a 96-well plate at 3000-4000/ well. After 24 hours, replaced the medium with RPMI 1640 culture medium as starvation. 24 hours after this, the cells were treated with BPA and DES at concentrations from $10^{-12} \mathrm{M}$ to $10^{-5} \mathrm{M}$, respectively. In joint effect assays, we added different compounds in an interval for at least one hour. After the treatment, the medium containing EDCs was removed, and $110 \mu \mathrm{L}$ of $0.25 \mathrm{mg} / \mathrm{ml} \mathrm{MTT}$ in medium culture was added to each well. The plate was incubated for $4 \mathrm{~h}$ at $37^{\circ} \mathrm{C}$. Then, culture medium was removed, and DMSO $(110 \mu \mathrm{l})$ was added into each well to dissolve the dark blue crystal. The absorbance was measured at $570 \mathrm{~nm}$ using a microplate reader. Cell viability was expressed as a percentage of the absorbance value of control cultures.

Statistical Analysis. All data are expressed as means and standard deviations (SD) from at least three determinations. For data analysis, student-t tests (SPSS) was used to determine the level of significance between the experiment group and the control groups. The treatments were considered significantly different at $\mathrm{p}<0.05$.

\section{Result}

Estrogenic Effect of BPA. To examine the estrogenic effect of BPA, initially we used MTT assay to measure the cell proliferation of MCF-7 cells treated with various concentrations of BPA ranging from $10-12$ to $10-5 \mathrm{M}$ for $24 \mathrm{~h}, 48 \mathrm{~h}$ and $72 \mathrm{~h}$ respectively. The result was reflected in Fig. 2.

We found there was a time-dependent manner for the proliferation of MCF-7 cells treated with BPA. As time goes on, the ability of BPA to provoke or inhibit cell proliferation was enhanced. The BPA barely showed significant cell proliferation with the concentration less than $0.1 \mathrm{nM}$. And statistically significant difference $(\mathrm{P}<0.05)$ was evaluated when treated with 1,10 and $100 \mathrm{nM} \mathrm{BPA}$. Otherwise, high-dose BPA inhibited proliferation, even showed slight cell toxicity in the highest concentration $(10 \mu \mathrm{M}$ BPA). The highest cell viability $(132.4 \%, \mathrm{P}<0.01)$ was achieved in $10 \mathrm{nM}$ BPA treatment, which was consistent with results of Song et al. ${ }^{[11]}$. In addition, another study found that the estrogenic activity of BPA increased via a dose-dependent manner in HeLa cells, and the most effective concentration is $1 \mu \mathrm{M}(\mathrm{P}<0.01)^{[12]}$, which indicated that estrogenic effect of BPA varied with different cells. We finally chose $10^{-8}$ and $10^{-11} \mathrm{M}$ BPA as experimental concentrations for joint 
assay with stimulation time of $72 \mathrm{~h}$. The concentrations of BPA in plasma collected from Hong Kong were $4.2 \times 10^{-9} \mathrm{M}^{[13]}$, which meant that the concentration $10^{-8} \mathrm{M}$ used for the joint assay is equivalent to the concentrations of BPA found inside your body.
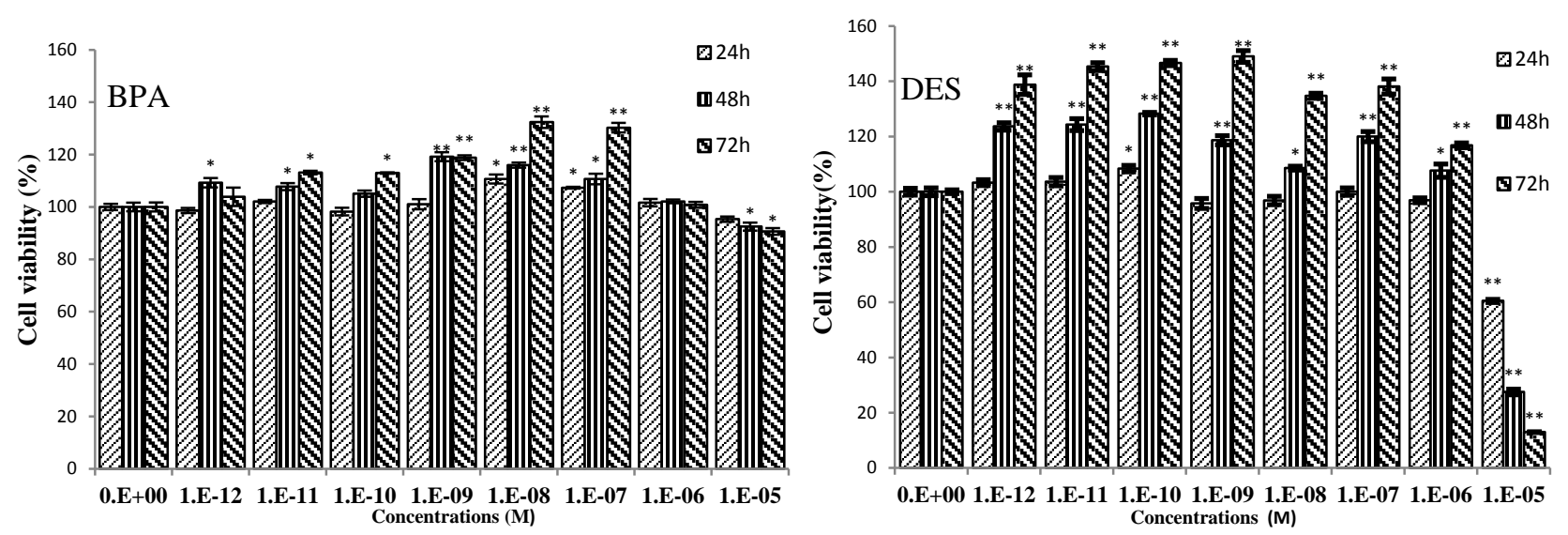

Fig. 2. Effect of BPA and DES treatment on proliferation of MCF-7 cells. ${ }^{*} \mathrm{p}<0.05$ compared with control group; ${ }^{* *} \mathrm{p}<0.01$ compared with control group.

Estrogenic Effect of DES. The result of MTT assay was shown in Fig. 2. Compared with BPA, it was even more obvious that the proliferation of MCF-7 cells treated by DES was increased via a time-dependent manner. In the stimulation time of $24 \mathrm{~h}$, most of the experiment group showed no significant differences compared with the control group, except for the treatment with $10 \mu \mathrm{M}$ DES. But the proliferation was increased rapidly with the prolonging of stimulation time. When treated with $1 \mathrm{nM}$ DES, the cell viability reached the highest value $(149 \%, \mathrm{P}<0.01)$. On the contrary, treated with $10 \mu \mathrm{M}$ DES, cells died via a time-dependent manner, which indicated that high-dose (less than or equal to $10 \mu \mathrm{M}$ ) DES was toxic and may lead to cell apoptosis. Finally, $10^{-9}$ and $10^{-6} \mathrm{M}$ DES was determined to be used for joint assay with stimulation time for $72 \mathrm{~h}$.

In comparison with BPA, the ability of DES to induce proliferation of MCF-7 cell was stronger. Leroy C. Folmar etc. also found that DES had greater estrogenic potency than either of the ste-roidal estrogens (17-estradiol, ethynylestradiol, diethystilbestrol, methoxychlor, nonylphenol) in MCF-7 cell proliferation assay ${ }^{[14]}$. In low dose, DES performed a more effective ability to induce cell proliferation. Furthermore, in high dose, DES also showed a much more intense toxicity for MCF-7 cells. Beyond that, we could find a semblable dose-dependent curve among them, especially in low dose, which was possible caused by their similar chemical structure. In brief, DES may be a more dangerous environmental contaminant than BPA. Fortunately, it could hardly be detected in the environment.

Estrogenic Effect of Binary Mixture of BPA and DES. Due to the complexity of the environment, humans were not always exposed to single contaminant but to mixtures of multiple environmental pollutants. "Combination effects" occurs when synthetic EDCs interact with each other, or with natural compounds in the environment and in the body, and they can have additive, synergistic or attenuative potential ${ }^{[15]}$. Therefore, we examined the joint effect of binary mixture of BPA and DES (shown in Fig. 3). The result showed that the binary mixture of $10 \mathrm{nM}$ BPA and $1 \mathrm{nM}$ DES strongly increased the proliferation of MCF-7 cells, which was a little more significant (163\%) than either single effect of $10 \mathrm{nM}$ BPA (135\%) or $1 \mathrm{nM}$ DES (150\%). And the same result was seen in the binary mixture (153\%) of $0.01 \mathrm{nM}$ BPA (113\%) and $1 \mathrm{nM}$ DES (150\%). This seemed like partial additive effect of the two EDCs. Indeed, when treated with the binary mixture (150\%) of $10 \mathrm{nM}$ BPA $(135 \%)$ and $1 \mu \mathrm{M}$ DES (113\%), the increasement of proliferation was more fierce, which was similar to the effect of the binary mixture (132\%) of $0.01 \mathrm{nM} \mathrm{BPA}(117 \%)$ and $1 \mu \mathrm{M}$ DES $(113 \%)$. These phenomena seemed like completely additive effect of the two EDCs.

These results reflected a fact that BPA and DES triggered cell proliferation in different mechanism. We hypothesized that these two EDCs affected in the same mechanism, and $1 \mathrm{nM}$ DES induced the 
highest proliferation (see in Fig. 2). According to the hypothesis, once BPA was added to the condition of $1 \mathrm{nM}$ DES, the cell viability should not increase. But the fact was opposite.

Joint Effect of E2, BPA and DES. E2 is an endogenous estrogen with the concentration of 0.01 $\mathrm{nM}$ to $10 \mathrm{nM}$ in human body. This was to say that once people were exposed to various EDCs, E2 would participate in the internal effect of human. Thus, it is urgent to explore the joint effect of E2 with other EDCs. Therefore, we selected $0.1 \mathrm{nM}$ E2 as the experimental concentration. In Fig. 3, we could find that the effect of $0.1 \mathrm{nM}$ E2 on cell proliferation was equal to $10 \mathrm{nM}$ BPA, which indicated that BPA was a weaker estrogen compared with E2. In joint effect assay, E2 enhanced the proliferation induced by single EDCs (0.1 nM E2, $10 \mathrm{nM}$ BPA, $0.01 \mathrm{nM}$ BPA or $1 \mathrm{nM}$ DES) with partial additive effect. However, there was an obvious antagonism when mixed $0.01 \mathrm{nM}$ E2 with $1 \mu \mathrm{M}$ DES. For ternary mixture of E2, BPA and DES, all the experimental groups performed an antagonism. The possible reason for that might be the competition between these three estrogens for estrogen receptors, including nuclear estrogenic receptors and membrane receptors.

Combination effects occurred when synthetic EDCs interacted with each other, or with natural compounds in the environment and in the body. Mixture constituents could act via common modes of action, or by a variety of signal transduction pathways which might crosstalk or produce other matrix effects $^{[16]}$. Because of this, the risk assessment of chemical mixtures became difficult. More information is needed regarding the biological effect of different compounds.
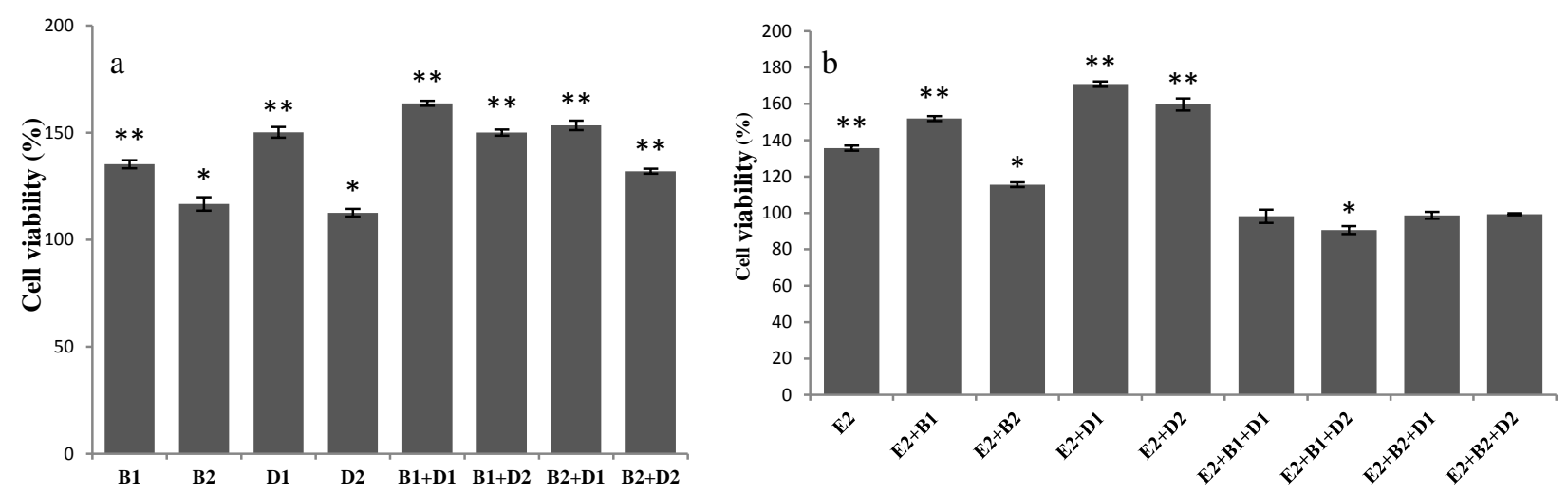

Fig. 3. Joint effect of BPA, DES and E2 on proliferation of MCF-7 cells. (a) MCF-7 cells were treated with binary mixture of BPA and DES. (b) MCF-7 cells were treated with mixture of E2, BPA or/and DES. The stimulation time is $72 \mathrm{~h} .{ }^{*} \mathrm{p}<0.05$ compared with control group; ${ }^{*} \mathrm{p}<0.01$ compared with control group. E2: $0.1 \mathrm{nM}$ E2; B1: $10 \mathrm{nM}$ BPA; B2: $0.01 \mathrm{nM}$ BPA; D1: $1 \mathrm{nM}$ DES; D2: $1 \mu \mathrm{M}$ DES.

\section{Summary}

In this paper, 1) we found that both of BPA and DES induced proliferation of MCF-7 cells in the same manner that promoted in low dose and inhibited in high dose $(1 \mu \mathrm{M})$. And DES had a stronger estrogenic effect than BPA. 2) The more intense effect would be realized when combined BPA with DES. 3) Binary mixture which combined $0.01 \mathrm{nM}$ E2 with BPA or low-dose DES could also induce greater proliferation. 4) But for ternary mixture of E2, BPA and DES, all the experimental groups performed an antagonism. Though the studies focus on mechanism would be the next work of our laboratory, we hoped these data could provide a basis for the research of EDCs and the evaluation of environmental health.

\section{Acknowledgements}

This research was sponsored by the National Natural Science Foundation of China (Grant Nos. 21567014 and 21267012). 


\section{References}

[1] C.M. Markey, B.S. Rubin, A.M. Soto, C. Sonnenschein, Endocrine disruptors from Wingspread to environmental developmental biology, J. Steroid Biochem Molec Biol. 83 (2003) 235-244.

[2] V.F. Fuhrman, A. Tal, S. Arnon, Why endocrine disrupting chemicals (EDCs) challenge traditional risk assessment and how to respond, J. Journal of hazardous materials. 286 (2015) 589-611.

[3] L.N. Vandenberg, I. Chahoud, J.J. Heindel, V. Padmanabhan, F.J.R. Paumgartten, G. Schoenfelder, Urinary, circulating, and tissue biomonitoring studies indicate widespread exposure to bisphenol A, J. Environ. Health Perspect. 118 (2010) 1055-1070.

[4] L.N. Vandenberg, R. Hauser, M. Marcus, N. Olea, W.V. Welshons, Human exposure to bisphenol A (BPA), J. Reprod. Toxicol. 24 (2007) 139-177.

[5] T. Geens, D. Aerts, C. Berthot, J.P. Bourguignon, L. Goeyens, P. Lecomte, G. Maghuin-Rogister, A.M. Pironnet, L. Pussemier, M.L. Scippo, J. Van Loco, A. Covaci, A review of dietary and non-dietary exposure to bisphenol-A, J. Food Chem. Toxicol. 50 (2012) 3725-3740.

[6] D.W. Kolpin, , E.T. Furlong, M.T. Meyer, et al., Pharmaceuticals, hormones, and other organic wastewater contaminants in US streams, 1999-2000: a national reconnaissance, J. Environmental Science \& Technology. 36 (2002) 1202-1211.

[7] Ye, X., Wong, L.Y., J. Kramer, et al., Urinary concentrations of bisphenol A and three Other bisphenols in convenience samples of US adults during 2000-2014, J. Environmental Science \& Technology, 49 (2015) 11834-11839.

[8] B.S. Rubin, Bisphenol A: an endocrine disruptor with widespread exposure and multiple effects, J. Steroid Biochem. Mol. Biol. 127 (2011) 27-34.

[9] A.L. Herbst, S. Anderson, M.M. Hubby, W.M. Haenszel, R.H. Kaufman, K.L. Noller, Risk factors for the development of diethylstilbestrol-associated clear cell adenocarcinoma: a case-control study, Am. J. Obstet. Gynecol. 154 (1986) 814- 822.

[10] E.E. Calle, C.A. Mervis, M.J. Thun, C. Rodriguez, P.A. Wingo, C.W. Heath, Diethylstilbestrol and risk of fatal breast cancer in a prospective cohort of US women, Am. J. Epidemiol. 144 (1996) 645- 652.

[11] H. Song, T. Zhang, P. Yang, et al., Low doses of bisphenol A stimulate the proliferation of breast cancer cells via ERK1/2/ERR $\gamma$ signals, J. Toxicology in Vitro. 30 (2015) 521-528.

[12] H. Hiroi, O. Tsutsumi, M. Momoeda, et al., Differential interactions of bisphenol A and 17 be-ta-estradiol with estrogen receptor alpha (ER alpha) and ER beta, J. Endocrine journal. 46 (1999) 773-778.

[13] H.T. Wan, P.Y. Leung, Y.G. Zhao, X. Wei, M.H. Wong, C.K. Wong, Blood plasma concentrations of endocrine disrupting chemicals in Hong Kong populations, J. Hazard. Mater. 261 (2013) 763-769.

[14] L.C. Folmar, M.J. Hemmer, N.D. Denslow, et al., A comparison of the estrogenic potencies of estradiol, ethynyl-estradiol, diethylstilbestrol, nonylphenol and methoxychlor in vivo and in vitro, J. Aquatic Toxicology. 60 (2002) 101-110.

[15] Y.W. Huang, J.R. Phillips, L.D. Hunter, Human exposure to medicinal, dietary, and environmental estrogens, J. Toxicological \& Environmental Chemistry. 89 (2007) 141-160.

[16] Johnson, C.M., Achary, M., \& Suri, R.P, An interaction model for estimating in vitro estrogenic and androgenic activity of chemical mixtures, J. Environmental science \& technology, 47 (2013) 4661-4669. 